\title{
Outdoor Learning Melalui Reboisasi Bagi Siswa Sekolah Dasar Desa Purwahamba
}

\author{
Outdoor Learning Through Reforestation For Primary School Students In Purwahamba \\ Village
}

\author{
Mujayanti', Devi Larasati ${ }^{2}$, Muhamad Fatih Idris ${ }^{3}$, Muhammad Tirto Sanyoto ${ }^{4}$, Tegar \\ Gagah Aditya ${ }^{5}$, Sesya Dias Mumpuni ${ }^{6}$ \\ ${ }^{1}$ Program Studi Pendidikan Bahasa Inggris, Fakultas Keguruan dan Ilmu Pendidikan, Universitas \\ Pancasakti Tegal, Indonesia \\ ${ }^{2}$ Program Studi Akutansi, Fakultas Ekonomi dan Bisnis, Universitas Pancasakti Tegal, Indonesia \\ ${ }^{3}$ Program Studi Teknik Mesin, Fakultas Teknik dan Ilmu Komputer, Universitas Pancasakti Tegal, \\ Indonesia \\ ${ }^{4,5}$ Program Studi Ilmu Hukum, Fakultas Hukum, Universitas Pancasakti Tegal, Indonesia \\ ${ }^{6}$ Program Studi Bimbingan dan Konseling, Fakultas Keguruan dan Ilmu Pendidikan, Universitas \\ Pancasakti Tegal, Indonesia \\ e-mail: ${ }^{1}$ mujayanti100@gmail.com, ${ }^{2}$ devilarasati534@gmail.com, ${ }^{3}$ fatih29idris@gmail.com, \\ ${ }^{4}$ sanyototirto7@gmail.com, ${ }^{5}$ tegargah@gmail.com, ${ }^{6}$ dias.mumpuni@upstegal.ac.id
}

\begin{abstract}
Abstrak
Kegiatan penghijauan yang dilakukan di Desa Purwahamba, Kecamatan Suradadi, Kabupaten Tegal adalah penghijauan dengan menanam tanaman pucuk merah. Selama ini lapangan di desa tersebut masih gersang karena sedikitnya tanaman yang ada di sekeliling lapangan. Maka dari itu team KKN Purwahamba 2021 mengusulkan program kerja pwnghijauan untuk pilar lingkungan. Setelah dilakukan diskusi dengan kepala desa, usulan tersebut diterima dan kami melanjutkan untuk survei lokasi serta membuat jadwal rencana kegiatan. Metode penyuluhan penghijauan ini menggunakan metode ceramah ilmiah dan praktik langsung. Penyuluhan penghijauan untukwarga dan siswa sekolah dasar dengan cara online. Team kkn dan organisasi karangtaruna membagikan link video yang berisi proses penanaman pohon dan cara pelestarian pohon, video tersebut diunggah di akun youtube kkn purwahamba 2021.
\end{abstract}

Kata kunci-penghijauan, pelestarian, pohon.

\begin{abstract}
The reforestation activity carried out in Purwahamba Village, Suradadi District, Tegal Regency is reforestation by planting red shoots. So far, the field in the village is still arid due to the lack of plants around the field. Therefore, the 2021 Purwahamba KKN team proposed a greening work program for the environmental pillar. After discussions with the village head, the proposal was accepted and we continued to survey the site and make a schedule of activity plans. This greening counseling method uses scientific lecture methods and direct practice. Greening counseling for residents and elementary school students online. The kkn team and the Karangtaruna organization shared a video link containing the tree planting process and how to conserve trees, the video was uploaded to the kkn purwahamba 2021 youtube account.
\end{abstract}

Keyword-afforestation, preservation, trees.

\section{PENDAHULUAN}

Dalam kehidupan, manusia akan selalu bergantung pada keberadaan pohon, begitu juga sebaliknya. Masing-masing dari keduanya memiliki peran penting dalam menjaga keseimbangan lingkungan. Pohon yang memberikan kehidupan dan berbagai sumber daya untuk manusia, dan manusia yang menjaga serta merawat pohon. Penghijauan merupakan salah satu bentuk peran manusia dalam menjaga lingkungan. Penghijauan ini dilakukan dengan melakukan 
penanaman pepohonan. Kita bisa lihat langkah penghijauan ini pada taman kota, pinggir jalan, atau di tempat- tempat yang berupa tanah lapang seperti yang dikutip dari "Dilihat dari faktor kesadaran masyarakat masih rendah atau kurang menunjang" (Nento \& Tueno, 2019).

Selain memberikan kesan segar dan memperindah pemandangan di tempat-tempat umum, penghijauan ini juga memberikan banyak manfaat bagi lingkungan. Pohon-pohon yang ditanam akan mengatasi polusi yang banyak dihasilkan di jalan raya, dan memberikan suplai oksigen bagi manusia. Manfaat penghijauan tidak hanya sampai di situ. Masih banyak manfaat penghijauan yang bisa dirasakan oleh lingkungan, khususnya manusia. Seperti kalimat yang dikutip "Cara penanganan yang tepat saat dan setelah terjadinya bencana tanah longsor merupakan hal yang sangat penting dimiliki oleh warga masyarakat sekitar daerah kejadian tersebut"(Fatiatun et al., 2019).

Salah satu pohon yang mudah ditanam dan ekonomis adalah pohon pucuk merah atau daun pucuk merah. Tanaman ini sering ditanam di pinggir jalan, halaman maupun di pekarangan rumah. Pucuk merah dapat diperbanyak bias dengan vegetatife dan cara generatife. Selain alas an keindahan, pohon ini ditanam karena memiliki akar tunggang yang mampu menghujam ke dalam tanah secara kokoh untuk merehabilitasi lahan, mencegah longsor dan menyimpan air. Seperti yang dikutip "pohon pucuk merah mempunyai morfologi daun berbentuk seperti jarum, permukaan licin dan bertajuk rimbun sebagai ciri tanaman mempunyai kemampuan tinggi mengurangi polutan“" (Ningsih, 2017).

"Lingkungan sekolah merupakan lingkungan pendidikan utama yang kedua setelah kelurga. “ (Martina, 2020). Sekolah merupakan lingkungan pendidikan yang secara sengaja dirancang dan dilaksanakan dengan aturan-aturan yang ketat seperti harus berjenjang dan berkesinambungan sehingga disebut pendidikan formal. Selain itu sekolah menyelenggarakan proses pembelajaran untuk mencapai tujuan. Pada kegiatan ini, team kkn berharap pada warga sekitar supaya untuk lebih peduli terhadap lingkungan. Maka dari itu kami mensosialisasikan kegiatan ini tidak hanya untuk orang dewasa namun dimulai dari anak sekolah dasar. Dengan cara menonton video menarik tentang penghijauan yang telah diunggah di akun youtube kkn purwahamba 2021 .

"This paper contributes to the growing body of research concerning use of outdoor spaces by educators, and the increased use of informal and outdoor learning spaces when teaching primary school children " according to (Harris, 2018). Outdoor education merupakan pendidikan lintas studi yang bertujuan untuk mendidik siswa memperoleh pengetahuan, pemahaman melalui interaksi langsung dengan alam sekitar. Pendidikan ini bias dilakukan di gunug, sungai, danau, kebun, taman, tempat ibadah, masyarakat, dan alam sekitar yang mudah dijangkau.

Penghijauan lingkungan merupakan salah satu program kerja dari KKN Purwahamba dalam pilar lingkungan, penghijauan ini dilaksanakan di lapangan Desa Purwahamba. Dalam hal ini kegiatan KKN di desa purwahamba adalah penghijauan hal ini pun atas dasar kebutuhan desa purwahamba. Di desa tersebut mempunyai rencana pembuatan taman desa yang lokasinya di sebelah atau samping lapangan desa Purwahamba (RT 11/07). Lapangan tersebut digunakan untuk kegiatan masyarakat mulai dari kegiatan bersekala kecil sampai bersekala besar seperti halnya kegiatan pertandingan sepak bola, latihan mobil, vestival agustus, acara besar islami, dan aktivitas masyarakat yang mengundag banyak orang. Alasan tim KKN Purwahamba memilih program kerja penghijauan yaitu karena kurangnya pohon pelindung di sekitar lapangan Desa

Purwahamba. Kegiatan ini merupakan kegiatan yang kebutuhan desa karena untuk meningkatkan kepedulian siswa dan masyarakat terhadap lingkungan yang ada di desa Purwahamba.

\section{METODE PELAKSANAAN}

Pelaksanaan program kerja ini menggunakan metode ceramah ilmiah dan praktik langsung. Kegiatan ini terbagi atas tiga tahapan yaitu tahapan perencanaan kegiatan, tahapan pelaksanaan kegiatan, dan tahapan evaluasi kegiatan. Kegiatan yang dilakukan pada tahap perencanaan

Outdoor Learning Melalui Reboisasi Bagi Siswa Sekolah Dasar Desa Purwahamba (Mujayanti, Devi Larasati, Muhamad Fatih Idris, Muhammad Tirto Sanyoto, Tegar Gagah Aditya, Sesya 
kegiatan antara lain berdiskusi bersama bapak kepala desa, melakukan survei lapangan, dan merancang jadwal kegiatan.

Tahapan pelaksanaan ini dilakukan di balaidesa desa Purwahamba, kecamatan Suradadi, kabupaten Tegal pada tanggal bulan Agustus 2021. Dan pada kegiatan ini kami memilih untuk menanam pohon pucuk merah. Alasan kami memilih pohon pucuk merah karena pohon pucuk merah mudah ditanam dan ekonomis. Team kkn menyumbang 50 bibit pohon untuk ditanam di desa Purwahamba. 40 bibit pohon ditanam di lapangan desa Purwahamba yang berlokasi tepatnya di RT $11 \mathrm{RW}$ 07. Dan sisa 10 bibit pohon akan ditanam oleh karangtaruna yang berlokasi di pinggir jalan yang menuju pedukuhan desa Purwahamba. Objek kegiatan ini adalah siswa-siswi SD dan masyarakat yang ada di desa Purwahamba. Pelaksanaan kegiatan ini dilakukan oleh tim KKN Purwahamba 2021 serta kepala desa dan organisasi masyarakat karang taruna yang ada di desa Purwahamba.

Pada tahapan evaluasi, yang dilaksanakan adalah dengan dilakukan penilaian antuasiasme warga terhadap kegiatan. kegiatan penghijauan ini diadakan pembuatan video yang berisi kegiatan atau cara penanaman pohon dengan baik beserta cara pelestariannya. Video tersebut di unggah pada akun youtube KKN Purwahamba 2021 yang selanjutnya link video tersebut dibagikan kepada para siswa dan masyarakat desa Purwahamba. Gambar 1 menunjukkan adanya diskusi bersama kepala desa Purwahamba.

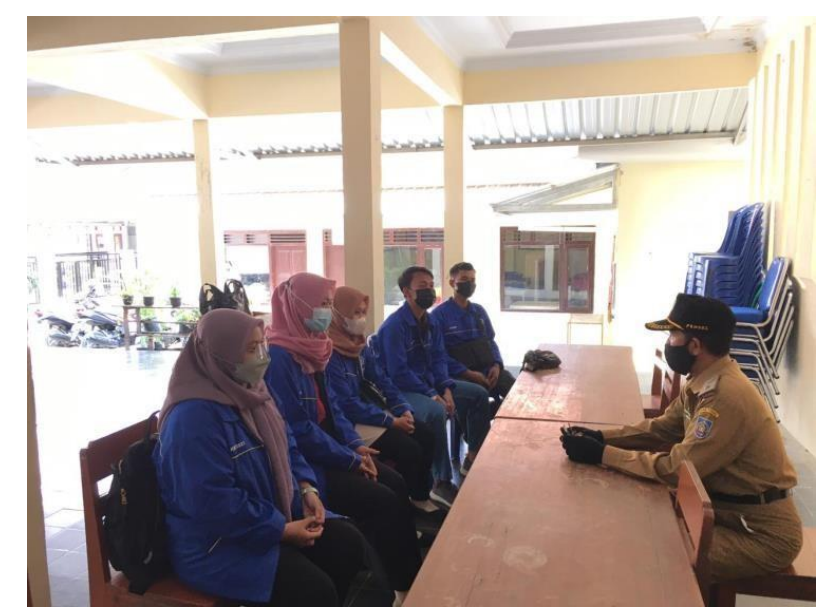

Gambar 1. Diskusi bersama Bapak Kepala Desa Purwahamba

\section{HASIL DAN PEMBAHASAN}

Dalam program kerja KKN Purwahamba 2021 yaitu penanaman pohon bisa memberikan edukasi terhadap siswa-siswi SD Purwahamba dan masyarakat Purwahamba. Dengan adanya penanaman pohon, siswa-siswi SD Purwahamba dan masyarakat Purwahamba dapat mengerti akan pentingnya merawat dan menjaga kelestarian bumi. Program kerja ini mendapat dukungan penuh dari Kepala Desa dan organisasi karang taruna desa Purwahamba. Kegiatan ini juga memberikan pemahaman yang mudah dimengerti oleh generasi penerus di masa yang akan datang. Selain memberikan edukasi dan pemahaman, program kerja ini juga untuk membangkitkan semangat kepada masyarakat dan pemuda Purwahamba untuk melanjutkan dan melestarikan apa yang sudah dilakukan oleh Tim KKN Purwahamba 2021. Pentingnya memberikan pemahaman ke[ada anak usia dini mudah di ingat dan sebagian siswa juga akan mempraktekan menanam di sekitar lingkungannya. Di sisi lain, hal ini juga dapat menjadi kegiatan rutin yang dapat diteruskan oleh organisasi masyarakat karang taruna desa Purwahamba.

Tim KKN Purwahamba 2021 juga memberi tahu jenis pohon yang ditanam di lapangan, di pinggir jalan ataupun di taman akan memberikan keindahan serta kenyamanan terhadap 
masyarakat. Adapun edukasi mengenai pohon yang memiliki akar tunggang yang mempunyai banyak manfaat untuk memperkuat tanah di sekitarnya dan memberikan efek rehabilitasi terhadap lahan dan berguna terhadap penyimpanan air di daerah tersebut. Adapun lingkungan sekolah yang paling utama setelah lingkungan masyarakat umum. Selain itu diharapkan kepada para guru tidak berhenti memberi pengetahuan tentang pentingnya pohon di lingkungan kita. Serta banyak berharap kepada warga untuk lebih peduli terhadap lingkungan. Tim KKN Purwahamba 2021 juga mensosialisasikan program kerja yang telah di kerjakan.

Dari pengamatan Tim KKN Purwahamba 2021 bahwa masyarakat desa Purwahamba masih kurang peduli terhadap kelangsungan kehidupan yang akan datang. Bukan hanya itu, kami juga memberikan evaluasi yang dilaksanakan dalam kegiatan penghijauan supaya tidak ada yang tidak mengerti dan memahami program kerja ini. Tim KKN Purwahamba 2021 juga menyarankan kepada Kepala Desa Purwahamba agar mengajak masyarakatnya senantiasa merawat dan menanam pohon di lingkungan desa maupun lingkungan rumah masing-masing warga. Adapun juga Ketua Karang Taruna desa Purwahamba yang lebih mudah mengajak para pemuda untuk melestarikan lingkungan, karena kebanyakan pemuda sekarang cenderung tidak memperhatikan kelestarian lingkungan dan alam, namun cenderung lebih menyukai teknologi dibandingkan menjaga dan merawat lingkungan. Hal kecil ini merupakan pengarahan yang baik terhadap generasi masa kini. Pemberian bibit pohon tidak hanya untuk ditanam di lapangan tapi juga diberikan kepada Kepala Desa Purwahamba dengan tujuan mengingatkan masyarakat agar tidak lupa untuk menanam bibit pohon dan melaksanakan penanaman bibit pohon di sekitar lingkungan rumahnya. Adapun juga sebagian masyarakat yang sudah sadar akan peduli terhadap lingkungan, sebagian yang lainnya masih acuh terhadap hal kecil di lingkungan rumah masyarakat seperti menanam pohon yang berbuah dan pohon yang rindang. Gambar 2 menunjukkan penyerahan bibit tanaman kepada Kepala Desa Purwahamba.

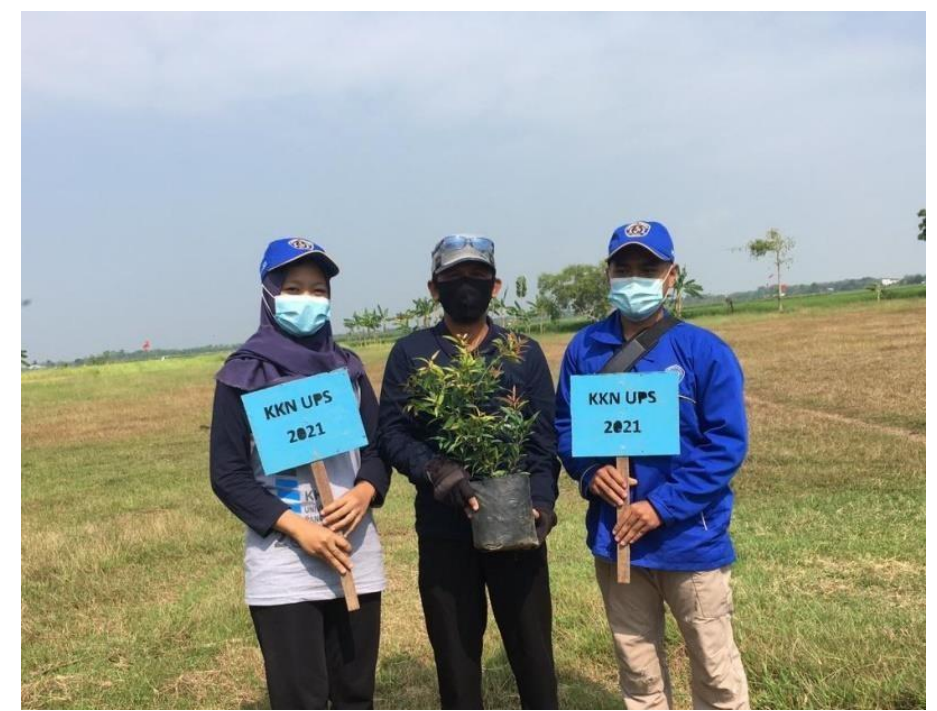

Gambar 2. Penyerahan Bibit Tanaman Kepada Bapak Kepala Desa Purwahamba

Dari sebagian yang peduli disebabkan mayoritas pekerjaan dan profesi masyarakat desa Purwahamba ada di luar kota dan sebagian lainnya berprofesi sebagai nelayan. Di lihat dari kondisi lingkungan, kontur tanah di musim kemarau sangatlah kering. Apabila tidak mulai menanam dari sekarang maka kedepannya akan berpotensi terjadinya kekeringan. Hal tersebut merupakan salah satu fungsi pohon sebagai resapan air di lingkungan sekitarnya. Hal ini disebabkan karena tidak mengerti pentingnya penanaman pohon dan manfaat pohon bagi mereka yang tidak peduli terhadap lingkungan sekitar. Bibit pohon dari program penanaman kali ini bukan ditunjukan untuk menanam pohon hias ataupun pohon lainnya. Apabila mengerti bibit pohon yang akan ditanam di lapangan, di pinggir jalan bahkan di lingkungan rumah harus

Outdoor Learning Melalui Reboisasi Bagi Siswa Sekolah Dasar Desa Purwahamba (Mujayanti, Devi Larasati, Muhamad Fatih Idris, Muhammad Tirto Sanyoto, Tegar Gagah Aditya, Sesya 
bias memilih pohon yang mempunyai manfaat lebih banyak. Hal ini harus bisa dimengerti dan dipahami terutama oleh masyarakat desa Purwahamba. Pemahaman ini yang tertera di atas bukan di maksudkan dan ditunjukkan untuk masyarakat dan pemuda tapi juga mengarah langsung ke generasi penerus terutama siswa-siswa SD Purwahamba, Apabila ditanam dari sekarang akan berpotensi baik terhadap keadaan lingkungan dan alam kedepannya bagi masyarakat yang melakukan penghijauan. Tidak ada dampak negatif dari penanaman bibit pohon melainkan keuntungan yang akan didapat di masa-masa yang akan datang.

Melihat keadaan alam yang sekarang, Tim KKN Purwahamba 2021 sangat ingin membantu dan menyadarkan manusia akan pentingna pohon bagi kehidupan masyarakat dan dunia .alam akan memberikan dampak yang baik apabila kita sebagai manusia yang mempunyai rasa kepedulian terhadap bumi agar dapat di rasakan di kehidupan yang akan datang. Gambar 3 menunjukkan adanya tim dari pengabdian masyarakat. Penanaman bibit pucuk merah dilakukan oleh tim dari pengabdian masyarakat. Pada Gambar 4 menunjukkan penanaman bibit pucuk merah.

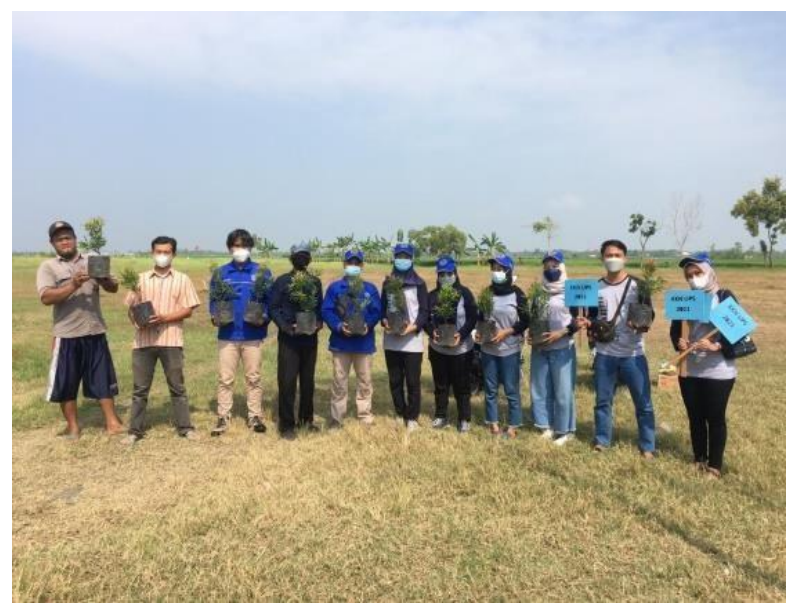

Gambar 3. Tim KKN bersama Bapak Kepala Desa Purwahamba dan Karang Taruna

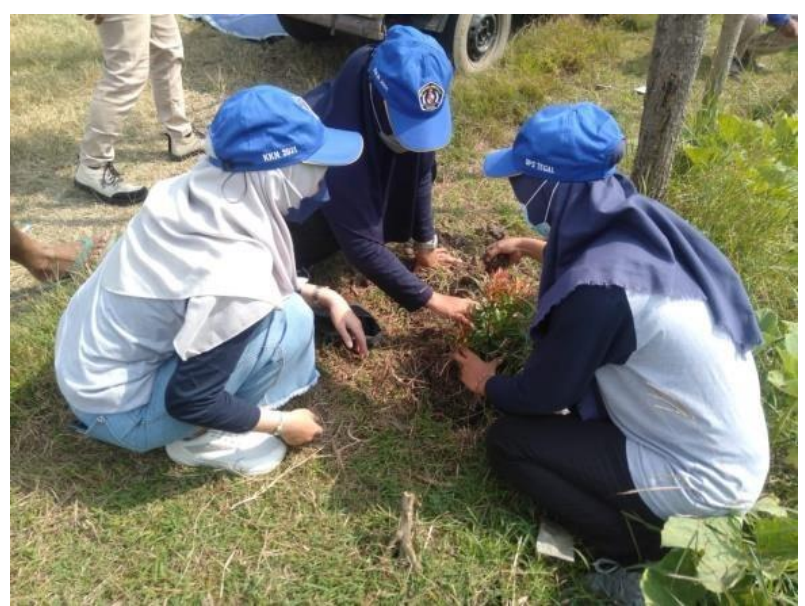

Gambar 4. Penanaman Bibit Tanaman Pucuk Merah

\section{KESIMPULAN}

Berdasarkan kuliah kerja nyata $(\mathrm{KKN})$ melalui kegiatan sosialisasi penghijauan di lapangan desa Purwahamba. Dapat disimpulkan bahwa warga masyarakat sekitar RT 14 dan warga sekolah dasar yang ada di desa Purwahamba, berjalan dengan baik dan mendapatkan respon yang baik. Terbukti dengan lancarnya kegiatan penanaman dan banyaknya view video yang ada di akun youtube kkn purwahamba 2021. Kegiatan penyuluhan penghijauan ini diharapkan 
membawa banyak manfaat dan ilmu pengetahuan tentang cara menanam bibit pohon serta pelestariannya.

\section{UCAPAN TERIMAKASIH}

Terimakasih kepada kepala desa Purwahamba, perangkat desa, organisasi karangtaruna, warga sekitar desa Purwahamba, Warga sekolah dasar dan Madrasah Islam Purwahamba, serta dosen pembimbing lapangan yang telah memberi banyak ilmu pelajaran dan pengalaman.

\section{DAFTAR PUSTAKA}

Fatiatun, F., Firdaus, F., Jumini, S., \& Adi, N. P. (2019). Analisis Bencana Tanah Longsor Serta Mitigasinya. Spektra: Jurnal Kajian Pendidikan Sains, 5(2). https://doi.org/10.32699/spektra.v5i2.113.

Harris, F. (2018). Outdoor learning spaces: The case of forest school. Area, 50(2). https://doi.org/10.1111/area.12360.

Martina. (2020). Pengaruh Lingkungan Sekolah Terhadap Hasil Belajar Siswa pada Mata Pelajaran Pendidikan Agama Islam di SMP Negeri 9 Tulung Selapan Kabupaten Oki. Jurnal Kapita Selekta Geografi, 3(2).

Nento, F., \& Tueno, N. S. (2019). Faktor-Faktor Penghambat Partisipasi Masyarakat Dalam Pelaksanaan Program Reboisasi Di Kecamatan.

Bulango Ulu Kabupaten Bone Bolango. Publik: Jurnal Manajemen Sumber Daya Manusia, Administrasi Dan Pelayanan Publik, 6(2). https://doi.org/10.37606/publik.v6i2.11.

Ningsih, W. R. (2017). Laju fotosintesis dan kandungan Pb daun pucuk merah. Prodising Seminar Nasional Pendidikan Biologi dan Biologi. 